\title{
Cotidiano
}

\section{AS FACES DA MELANCOLIA: PULSÃO DE MORTE, SUPEREU E ATO EM FLORBELA ESPANCA}

Débora dos Santos Silva (1). Raul Max Lucas da Costa (2).

\begin{abstract}
Resumo
$\mathrm{O}$ artigo pretende analisar os mecanismos envolvidos no processo melancólico de Florbela Espanca, poetisa portuguesa do início do século XX, tentando responder se a escrita literária e confessional conseguiu conter, à maneira de sublimação, uma dor profunda de viver que caracterizava a tristeza manifesta em sua vida. Para esta finalidade utilizou-se a metodologia de pesquisa bibliográfica sobre a melancolia, a partir da perspectiva freudiana que trabalha com as categorias: pulsão de morte, conflitos entre Eu e Supereu e culpa; e, lacaniana, que enfatiza ideias sobre gozo, identificação com o objeto $a$ enquanto dejeto, e ato suicida como tentativa de fazer barra aos imperativos do Supereu. Examinou-se também teóricos da literatura acerca da obra da poetisa, além de seus relatos íntimos contidos em sua correspondência, e alguns de seus poemas. Estes retratavam o quanto sua escrita era cheia da melancólica sensação de angústia, de tristeza e de morte. Nesse sentido, faz-se uma interseção entre psicanálise e literatura buscando ampliar os debates sobre a patológica melancolia e uma de suas consequências: o suicídio.
\end{abstract}

Palavras-chave: Pulsão de morte; Supereu; Gozo; Florbela; Ato suicida. 


\section{Introdução}

A melancolia é uma patologia que consome todas as energias: tanto as direcionadas aos objetos externos quanto as dirigidas para o próprio Eu. Sendo que esta perda energética pode levar o sujeito ao ato suicida na busca de acabar com o vazio e ao mesmo tempo aplacar a dor. Florbela Espanca, poetisa portuguesa, experimentou do sombrio humor que atinge um melancólico, tristeza tenaz que na poetisa não teve início nem fim. Pretende-se com a pesquisa analisar o processo melancólico em Florbela e como este se refletiu em sua escrita literária e confessional. Seguiu-se o método de pesquisa bibliográfica atrelado ao recurso do estudo de caso. Nesse sentido, enfocou-se as concepções psicanalíticas, os relatos feitos por estudiosos da literatura sobre a obra da poetisa e alguns de seus poemas.

Portanto, o texto será permeado inicialmente pelas ideias freudianas sobre a melancolia, enfatizando o conflito entre as instâncias psíquicas: Eu e Supereu, onde o primeiro se coloca numa posição masoquista diante do sadismo do último que, em virtude da disjunção pulsional, tomou para si a energia destrutiva da pulsão de morte. Depois, será trazida à tona a perspectiva lacaniana sobre a melancolia, que estaria referida a um real não passível de simbolização. Revelando em sua gênese uma ausência do olhar da mãe a confirmar a imagem do bebê durante o estádio do espelho, levando o sujeito a se identificar com o nada.

Posteriormente, com a bússola que a teoria pode proporcionar, será descrito alguns aspectos da história de vida de Florbela a partir da perspectiva de certos teóricos da literatura e dos relatos constantes em suas cartas. Além de recorrer a alguns de seus poemas no sentido de melhor vislumbrar a manifestação melancólica em sua escrita.

Enfim, busca-se analisar o mecanismo atuante na melancolia de Florbela e tentar responder à seguinte questão: A escrita literária e confessional conseguiu conter, à maneira de sublimação, uma dor profunda de viver que caracterizava a tristeza manifesta em sua vida e obra? Esta melancolia se caracteriza por uma manifestação narcísica, psicótica ou se deve a outro estatuto?

\section{Método}

Para desenvolver a pesquisa os autores pautaram-se no estudo qualitativo e de caráter bibliográfico que segundo Gil (1999), 
[...] tem como principal vantagem [...] [o] fato de permitir ao investigador a cobertura de uma gama de fenômenos muito mais ampla do que aquela que poderia pesquisar diretamente [...] [Sendo que tal] vantagem torna-se particularmente importante quando o problema de pesquisa requer dados muito dispersos pelo espaço [...] A pesquisa bibliográfica também é indispensável nos estudos históricos. Em muitas situações, não há outra maneira de conhecer os fatos passados se não com base em dados bibliográficos (GIL, 1999, p.45).

Procurou-se, assim, manipular as categorias: pulsão de morte, disjunção pulsional, conflitos entre $\mathrm{Eu}$ e Supereu e gozo, presentes na bibliografia consultada, a fim de compreender o funcionamento destes conceitos metapsicológicos aplicados ao recurso do estudo de caso. Lembrando que,

[...] existem três diferentes tipos para se utilizar o método de estudo de caso: estudo de caso intrínseco ou estudo de caso único (fato, objeto, fenômeno), estudo de caso instrumental (definido dentro de um modelo teórico) e o estudo de caso múltiplo (estudo entre duas ou mais realidades ou situações). (MUCCHIELLI citado por OLIVEIRA, 2008, p. 56, grifos do autor).

Utilizou-se, pois, dentre os três tipos de estudos de caso citados, o estudo de caso instrumental. Por considerá-lo apropriado ao lance do olhar acerca do objeto de estudo: o processo melancólico em Florbela a partir do embasamento teórico psicanalítico, coberto pelo levantamento bibliográfico.

Nesse sentido, deu-se prioridade aos textos psicanalíticos de perspectiva freudiana e lacaniana, e à leitura da poesia florbeliana, especialmente os livros: Charneca em flor (1931), onde se destaca o soneto "Mendiga" e Reliquiae (1934) com ênfase ao soneto "Deixai entrar a morte".

Além dos próprios livros de poemas da escritora, buscou-se os relatos feitos por alguns estudiosos da literatura sobre a sua obra, dentre eles, Faria Filho (2006), Moreno (2007) e Dal Farra (2002), esta última biógrafa e organizadora de suas obras no Brasil, que melhor inteirou os autores dos hábitos da poetisa e dos relatos íntimos contidos nas cartas e diário do último ano de vida de Florbela. 


\section{Revisão da literatura}

\section{A Evolução do Pensamento Freudiano acerca da Melancolia}

Na correspondência dirigida a Fliess entre 1892 e 1899, precisamente nos rascunhos E, G e K, já se destacam as hipóteses de Freud sobre a melancolia. Naquele momento de seus estudos a melancolia era comparada às neuroses atuais: neurose de angústia e neurastenia, e como tal a afecção estava relacionada a problemas na esfera do exercício da sexualidade e não a questões concernentes à história infantil do sujeito.

Enquanto na neurose de angústia a tensão sexual acumulada seria física, na melancolia a tensão sexual acumulada seria psíquica. Enquanto na neurastenia haveria uma hemorragia libidinal na esfera sexual somática, na melancolia haveria uma hemorragia libidinal, um buraco, na esfera psíquica. Nesse sentido é que os melancólicos sofreriam de anestesia sexual psíquica. Ou seja, “[...] Não têm necessidade de relação sexual [...] Mas têm um grande anseio pelo amor em sua forma psíquica [...] Nos casos em que esta se acumula e permanece insatisfeita, desenvolve-se a melancolia [...]"(FREUD, 2006[1892-1899]), p. 237).

Com um raciocínio um pouco diferente, em Luto e melancolia, de 1917, Freud, como o próprio título do artigo sugere, busca distinguir o afeto envolvido na melancolia do envolvido no luto. Diz que o principal fator diferenciador entre os afetos citados que se assemelhariam na inibição da vontade, desinteresse pelo mundo externo e suspensão da capacidade de amar, é a depreciação do sentimento de si. Observa-se que para o sujeito enlutado "[...] o mundo tornou-se pobre e vazio [...]" (FREUD, 2006[1917], p. 105) enquanto que para o sujeito melancólico "[...] foi o próprio Eu que se empobreceu [...]” (FREUD, 2006[1917], p. 105). Freud, pois, chama atenção para a grande peculiaridade melancólica: a capacidade que o sujeito adquire de se recriminar, de se considerar sem valor, medíocre.

Ainda neste texto, Freud dá explicações referentes à gênese da melancolia. Logo, subjacente à sua manifestação estaria: uma perda objetal na vida do sujeito (morte, decepção, abandono de um ideal). A libido retirada, desinvestida do objeto não é reinvestida, mas regressa ao Eu. Ao regressar, a libido não é utilizada para enriquecimento do Eu e sim para identificação do Eu com o objeto perdido ou abandonado. Esta identificação termina por empobrecer o Eu, pois “[...] a sombra do objeto caiu sobre [...] [ele]" (FREUD, 2006[1917], p. 108). O resultado de todo esse mecanismo, segundo o autor, seria o delírio de insignificância, insônia, recusa a alimentar-se que o sujeito dirige a si mesmo. 
Em Além do princípio de prazer, de 1920, Freud destrincha todas as nuances envolvendo a pulsão de morte. Ele investiga alguns eventos que contrariam a noção de que o aparelho psíquico trabalha em busca de evitar o desprazer e de, por conseguinte, produzir prazer. Depara-se com situações reveladoras de uma verdadeira "compulsão à repetição", compulsão referida a acontecimentos penosos que, por mais que causem sofrimento na vida do sujeito, insistem em se reproduzir dando a impressão de existir a força do destino subjacente a eles. Portanto, foi através da observação da compulsão à repetição que Freud despertou para a possibilidade de uma pulsão de morte que buscaria reduzir a zero a soma de excitação no aparelho psíquico.

Assim, a pulsão de morte seria representada pelo princípio de nirvana, força poderosa capaz de vencer o princípio de prazer, representante da libido, e o princípio de realidade, representante do mundo externo (FREUD, 2007[1924]).

No texto $O$ mal estar na civilização, de 1930, Freud faz uma descrição relevante acerca das ações humanas que denunciam os efeitos da pulsão de morte voltada para o mundo externo em forma de agressividade. Logo, a agressividade faria parte de uma inclinação humana e esta inclinação se constituiria enquanto causa das perturbações existentes em seus relacionamentos, provocando grande dispêndio de energia para contrabalançá-la. Sendo que da conjunção entre pulsões de vida e pulsão de morte surgiriam três derivados, a saber: sexualidade, destruição e vontade de poder (QUINET, 2009).

No caso da melancolia haveria uma disjunção das pulsões. Assim, a agressividade não estaria direcionada para o mundo externo, mas para dentro do sujeito, onde o Eu termina por tornar-se objeto de crítica do Supereu: instância herdeira do Complexo de Édipo, representando, de um lado, os resquícios das antigas escolhas objetais do Id, e de outro, uma formação reativa contra elas (FREUD, 2006[1923]). “[...] O supereu mergulha suas raízes no isso e, de uma maneira implacável, exerce as funções de juiz e censor em relação ao eu [...]”(ROUDINESCO, e PLON, 1998, p.744, grifo dos autores).

Nesse prisma, em O problema econômico do masoquismo, de 1924, Freud descreve o masoquismo moral, caracterizado como sentimento inconsciente de culpa e necessidade de punição, proveniente do recalque da pulsão agressiva frente ao mundo externo e de seu retorno para o Eu. Situação aparentemente presente na melancolia, onde o sadismo do Supereu se une ao masoquismo do Eu para aniquilar o desejo de vida do sujeito e inseri-lo na busca por autodestruição.

Sobre a culpa, Mannoni (1994) referindo-se aos mistérios envolvidos em seu mecanismo no pensamento freudiano, diz que ela é a manifestação de um crime intentado na 
fantasia e nos anseios infantis. Assim, "[...] As satisfações, disfarçadas, secretas, latentes, manifestam-se por sintomas: a culpa pode ser equiparada a esses sintomas [...]" (MANNONI, 1994, p. 173, grifo do autor). O Supereu, conhecedor da fantasia e dos anseios criminosos pelo sujeito alimentado durante a infância e mesmo na vida adulta, termina por assumir uma conduta rígida para com o Eu culpado.

Ademais, na trilha dos conflitos entre as instâncias psíquicas que ocasionariam a dor melancólica, Carneiro et al. (2006) ao se referirem ao artigo Neurose e Psicose, de 1924, dizem que Freud define o estatuto da melancolia, enquanto conflito entre Eu e Supereu, no rol de neurose narcísica, contrastando, portanto, com o das neuroses transferenciais onde o conflito estaria situado entre o Eu e o Id, e as psicoses, cujo conflito se situaria entre o Eu e o mundo externo.

Na melancolia, o Supereu que exerce as funções de observação, consciência, e veículo do ideal do eu, se revelaria "[...] perverso, insulta, humilha e maltrata o pobre [...] [Eu] ameaça-o com os mais duros castigos [...] aplica o mais rígido padrão de moral ao [...] [Eu] indefeso que lhe fica à mercê [...]"(FREUD, 2006[1933], p. 66)'

Uma forma de o Eu fazer frente ou triunfar ante o Supereu no processo melancólico, seria uma mudança para a mania. Entretanto, “[...] isto não acontece com todos os casos de melancolia. Alguns casos apresentam recidivas periódicas, com intervalos nos quais não se apresenta nenhuma mania ou só uma nuance muito tênue de mania [...]" (FREUD, 2006[1917], p. 112).

O que aconteceria nos casos onde a díade melancolia/mania é inexistente? Será que neles o sujeito sempre declina e cede à mortificação, ao suicídio, onde a disjunção entre pulsões de vida e pulsão de morte não refletem o aspecto de renovação, de vontade de começar com novos custos, apontado por Garcia-Roza (2004), e sim uma zerificação da vontade de viver? Neste sentido, o sujeito mergulharia inevitavelmente no eterno repouso do princípio de nirvana através do ato de destruir-se a si mesmo? Haveria outra possibilidade de desfecho para a condição melancólica?

\section{A Perspectiva Lacaniana sobre a Melancolia}

Quinet (2009), comentando Lacan, diz que a melancolia é um tipo clínico de psicose e, assim, revelaria uma falta de referência ao Nome-do-Pai. Que, segundo o autor, Lacan faz equivaler ao Complexo de Édipo enquanto nó que tanto mantém unido quanto promove a 
diferenciação entre Real, Simbólico e Imaginário. Este quarto nó é que permitiria a entrada do sujeito nos laços sociais: barrando o gozo.

Já que, segundo Valas (2001), o Nome-do-Pai exerce duas funções. Sendo, portanto, apoio da Lei a partir de onde se norteia o desejo, além de permitir a existência de uma economia de gozo. Ou seja, o Nome-do-Pai traduz a metáfora paterna que promove a deposição do lugar alienante em que a criança originalmente se encontra de ser o falo da mãe, para que possa existir separada desta e se estabelecer enquanto sujeito desejante (COSTA, 2010).

Nesse sentido, Valas (2001) menciona o aspecto nocivo do gozo, posto ser o limiar da aniquilação do sujeito na medida em que não faz parte da cadeia significante e sim de um real sentido no corpo. Assim é que o conceito de gozo, inserido por Lacan, designaria a pulsão de morte conceituada por Freud.

O gozo é contrário ao desejo que é o correspondente da Lei. O desejo sendo, por sua vez, fundado pela entrada do sujeito na linguagem (FINK, 1998). Na psicose, o gozo refere-se aos significantes que retornam dispersos no real (VALAS, 2001), a partir de sua foraclusão no simbólico. Demonstrando a difícil condição do psicótico que mesmo tentando dialetizar o real, termina por naufragar em sua tentativa de achar um significante que o determine na medida em que se encontra, estruturalmente falando, fora-do-discurso, foracluído do Nomedo-Pai (QUINET, 2009).

Contudo, se todo ato é um dizer, embora fazendo parte do campo do gozo onde impera o silêncio da pulsão de morte, o ato psicótico apresentaria, segundo Quinet (2009), duas vertentes, a saber: pode representar um ataque ao outro como tentativa de fazer barra ao gozo ou pode representar uma tentativa de cura enquanto forma de recorrer ao outro da Lei para se inserir no laço social. Trazendo para a problemática da melancolia, o ato suicida poderia representar tanto uma negação ao gozo, aos imperativos da voz do Outro introjetada enquanto Supereu, como também uma busca por parte do Eu para imortalizar-se. Passar do real da dor e do esquecimento para a quietude da morte e as honras do tempo.

Ademais, segundo o autor, existiria na melancolia uma frouxidão do desejo, onde o sujeito abrindo mão deste desejo que se fundamenta numa falta a ser, numa sede de saber, terminaria por transformar a falta estruturante em falta moral e sentimento de culpa. Neste sentido, ao perder aquilo que preenchia a foraclusão do Nome-do-Pai, o sujeito se veria defrontado à identificação com o objeto $a$ enquanto dejeto, vazio, nada, sobrevindo, pois, a imensa dor melancólica: a dor de existir (QUINET, 2009). 
Além disso, Brasil (2001), referindo-se às concepções de teóricos como Lambotte e Hassoun, menciona que na origem da melancolia encontra-se a falta do olhar da mãe que confirme a imagem do bebê no espelho. Haveria, pois, um olhar que o olha, mas não o vê. Portanto, a autora faz menção ao estádio do espelho que, segundo Lacan,

[...] é um drama cujo impulso interno precipita-se da insuficiência para a antecipação - e que fabrica para o sujeito, apanhado no engodo da identificação espacial, as fantasias que se sucedem desde uma imagem despedaçada do corpo até uma forma de sua totalidade que chamaremos de ortopédica - e para a armadura enfim assumida de uma identidade alienante, que marcará com sua estrutura rígida todo o seu desenvolvimento mental [...] (LACAN, 1998, p. 100).

Segundo Brasil (2001) o sujeito se identifica com o olhar enfraquecedor da mãe para a constituição da imagem e assume uma repugnância para com o próprio Eu.

Hassoun (2002) diz sobre essa mãe não confirmadora da imagem do bebê no espelho que ela “[...] não é uma distraída. Ela é ausente para seu filho e para aquele que ocuparia, em relação a ela, uma posição de pai. Ela só está presente para si mesma [...]” (HASSOUN, 2002, p. 65), ocupada em admirar sua própria imagem. Para este autor haveria na melancolia uma impossibilidade de fazer o trabalho do luto, a elaboração da dor, justamente pela ausência de uma relação estruturante com o Outro.

Porém, segundo Brasil (2001) haveriam tentativas geralmente utilizadas de saída desta identificação com o objeto resto da melancolia, a saber: "[...] autocrítica e refúgio na intelectualidade [...] prazer da expulsão e do rechaço de qualquer investimento e o desdém pelo mundo [...]" (Brasil, 2001, p. 12). Além dessas, a autora menciona o enamoramento que, contrariando o tédio e a cortesia endereçados pelo melancólico aos demais, ante as relações amorosas esta atitude tenderia a desvanecer, surgindo, em contrapartida, uma intensa ambivalência afetiva.

Sobre as tentativas empreendidas pelo sujeito para sair da melancolia, Hassoun (2002) faz referência aos autores que parecem marcar seus trabalhos artísticos da melancolia que os aflige, e diz, neste sentido, que hipoteticamente

[...] cada uma de suas produções é, em si mesma, uma tentativa de criar um objeto próprio que lhes permita efetuar um trabalho de luto, luto que se cumpre graças ao texto escrito, publicado, e portanto oferecido ao Outro. Essa atividade, atravessada por uma sublime melancolia, não encontra contudo sua resolução, como se, a cada 
vez, o objeto fosse incapaz de se constituir. A escritura, em vez de produzir um alívio, alimenta na verdade o enigma de uma insondável crueldade, semelhante àquela que se inflige o melancólico, desde sempre confrontado a uma perda de que não pode desenhar os contornos [...] (HASSOUN, 2002, p. 152).

A passagem ao ato, pelas vias do suicídio, remeteria a outra tentativa de achar um lugar no desejo do Outro ou de fazer uma falta no Outro, esse que olha e não vê, mesmo que isso signifique o fim da própria vida (RAMALHO, 2001).

\section{As Faces da Melancolia em Vida e Obra de Florbela}

A partir da leitura do texto Afinado desconcerto (contos, cartas e diário) de Dal Farra (2002), biógrafa e organizadora das obras de Florbela no Brasil, foi possível conhecer a história de vida da poetisa.

Flor Bela d'alma da Conceição Espanca teve uma existência cheia de acontecimentos dolorosos. Contados a partir de seu nascimento na cidade de Vila Viçosa, Portugal, em 08 de dezembro de 1894, fruto de um relacionamento extraconjugal. Criada na casa paterna, ao lado da esposa de seu pai que era estéril e longe da mãe biológica. Seus três casamentos fracassados. Os dois abortos sofridos. A morte de Apeles, seu irmão, quando do acidente envolvendo o hidroavião que pilotava por sobre o rio Tejo. Até sua própria morte pela via do suicídio, em 08 de dezembro de 1930, na cidade de Matosinhos ${ }^{1}$.

Sendo que, todo o seu talento literário parece ter se voltado a uma tentativa de elaboração das angústias e decepções vivenciadas numa sociedade onde, segundo Moreno (2007), a mulher embora assumindo outros papéis que não apenas o de reprodutora e cuidadora dos filhos, mas também trabalhando fora de casa para auxiliar na renda familiar, ainda era encarada no que tange às manifestações intelectuais, sexuais e até econômicas como inferior ou incapaz. No que diz respeito à educação,

No final do século XIX e início do século XX, as oportunidades de ingresso no mundo acadêmico para a mulher eram extremamente reduzidas. Escolas estatais secundárias só permitiam, na prática, o acesso feminino após 1906. Até então, algumas moças, muito determinadas, cursavam os liceus masculinos. Não se deve esquecer que era um número insignificante, estatisticamente falando. Para a sociedade da época, o aprendizado feminino não deveria ir além das prendas 
domésticas, considerando-se o ensino escolar até como nocivo (MORENO, 2007, p. 19).

Florbela foi exatamente uma das primeiras mulheres a ingressar no Liceu de Évora onde havia a presença maciça do público masculino (FARIA FILHO, 2006).

Neste sentido, adverte Faria Filho (2006) que a obra da poetisa foi muito criticada por subverter o papel feminino, ao dar expressão a sentimentos que deveriam, segundo os critérios da sociedade da época, permanecer escondidos. O conteúdo de seus escritos recheados de erotismo, de sonhos, de infortúnio e de morte dificultou a publicação de seus livros por falta de interesse das editoras. Portanto, Florbela conseguiu publicar em vida apenas dois livros: Livro de mágoas (1913) e Livro de Sóror Saudade (1923), com ajuda financeira do pai.

Sua escrita literária, a exemplo do poema por ela criado em 1903, intitulado $A$ vida e a morte, gira em torno destes dois grandes temas que perpassam os conflitos humanos (Dal Farra, 2002). Nesse sentido, ela demonstrava em seus versos o que as demais pessoas buscam evitar na correria do cotidiano, nos entretenimentos e diversões, a saber: "a dor de existir" segundo Quinet (2009) ou a “dor cósmica” que segundo Dal Farra (2002) possibilitou a Florbela a criação de uma obra tão rica.

Acrescidos das incompreensões e dificuldades que vivenciou por ser mulher poetisa num momento histórico pouco propício às expressões sentimentais femininas, existia em Florbela, desde a infância, uma profunda tristeza que o tempo só fez aumentar, devido às perdas enfrentadas, inclusive os dois abortos sofridos. Abortos que Barros (2010) coloca como hipótese de contributo ao processo melancólico em Florbela, já que segundo a autora “[...] O aborto pode trazer sentimentos de perda causando uma dor psíquica intensa [...] pode ser considerado [...] um tipo particular de luto [...] refletida, [...] no corpo [...]" (BARROS, 2010, pp. 118-19).

Percebe-se na correspondência e no diário de Florbela a tentativa de compreender, de explicar a razão de sua dor. Sobre sua grande sensibilidade, a poetisa escreve em uma de suas cartas a Guido Battelli, professor italiano visitante na Universidade de Coimbra, Portugal, as seguintes palavras: [...] Eu sou hoje o que fui sempre [...] Tive sempre esta mesma sensibilidade doentia, esta profunda e dolorosa sensibilidade que um nada martiriza [...] (ESPANCA, 2002, p. 277). 
Em outra carta, cerca de quatorze anos antes daquela direcionada a Battelli, dirigida a Julia Alves que era diretora adjunta de um suplemento no jornal da época denominado $O$ século (FARIA FILHO, 2006), Florbela diz sobre a história de sua tristeza:

[...] Eu não sou feliz mas nem ao menos te sei dizer porquê. Nasci num berço de rendas rodeada de afectos, cresci despreocupada e feliz, rindo de tudo, contente da vida que não conhecia, e de repente [...] no alvorecer dos meus 16 anos, compreendi uma coisa que até ali não tinha compreendido e parece-me que desde esse instante cá dentro se fez noite [...] Falta-me o meu castelo cheio de sol entrelaçado de madressilvas em flor; falta-me tudo que eu tinha dantes e que eu nem sei dizer-te o que era [...] (ESPANCA, 2002, p. 222).

Nesta carta Florbela descreve justamente o vazio que de repente, no amanhecer de seus dezesseis anos, viu transformar-se a vida como se uma hemorragia libidinal, uma perda pulsional tivesse se dado e deixado consigo apenas dor, angústia, desalento.

É interessante constatar que a tristeza e a saudade do que tinha, mesmo sem saber o que era, e se perdeu, tão acalentada por Florbela, de certa forma traz à tona o sentimento saudosista que parece perpassar a história do povo português em geral que, segundo Teixeira Pascoaes (1877-1952)2, citado por Garmes e Siqueira ${ }^{3}$ (2009) seria “[...] uma raça diferenciada das outras nacionalidades européias. Uma raça que possui maior sensibilidade para a condição saudosa e, portanto, sofre mais do que as outras [...]” (GARMES, e SIQUEIRA, 2009, p. 105), a saudade para ele faria parte da alma portuguesa, numa referência a um estado de perfeição original há muito perdido. Pensamento muito semelhante ao de Freud quando revela que as pulsões (de vida e de morte), cada uma a sua maneira, buscariam restaurar um estado que fora perturbado pelo início da existência (FREUD, 2006[1923]).

Porém, ao examinar-se a correspondência de Florbela percebe-se a presença não só do sentimento de saudade de algo que se foi: o que caracterizaria a existência de um luto ante a perda de um objeto, mas também de acusações e recriminações que dirige a si mesma, ansiando pela morte como maneira de aplacar a dor: características melancólicas. Desta correspondência, destacam-se dois fragmentos:

A Julia Alves,

[...] vou descrever-lhe desde já o meu péssimo carácter: sou triste, imensamente triste, duma tristeza amarga e doentia que a mim própria me faz rir às vezes. É só disto que eu rio, e aqui tem já [...] no meu caráter uma sombra negra, enorme, 
medonha: a hipocrisia!... Porque eu pareço alegre e toda a gente gaba a minha... alegria! [...] O segundo [defeito] [...] é o sonhar, sonhar muito, olhar muito além, para longe de todos os que cantam, os que falam, os que riem!...[...] Mãe já a não tenho há muito; tenho 22 anos e não me recordo nem da cor dos seus cabelos; irmãs nunca tive, e amigas tenho as que toda a gente tem [...] Eu sou refractária a todas as altas questões de elegância [...] sou indigna, como vê, do seu interesse, das suas boas palavras e da sua alta e enternecida bondade [...] (ESPANCA, 2002, p. 207).

A Guido Battelli,

[...] Nada me chega, nada me convence, nada me enche. Sou um pobre que nenhum tesoiro acha digno das suas mãos vazias. A morte, talvez... esse infinito, esse total e profundo repouso [...] Pense bem: eu, que não sei o que é dormir uma noite inteira, dormir muitas, dormir todas e todos os dias e todos os anos, pelos séculos dos séculos! Só esta ideia me faz sorrir. Deve ser tão bom! (ESPANCA, 2002, p. 275).

Ecoa das palavras de Florbela um sentimento de culpa e indignidade que talvez advenha da falta moral em ceder de seu desejo restando apenas a morte como possibilidade de acabar com o conflito, de fazer barra ao gozo do Supereu.

Ademais, Dal Farra (2002) citando José Gomes Ferreira, contemporâneo de Florbela quando a mesma cursava Direito na Universidade de Lisboa, acena a hipótese de que a escritora desprezava e desdenhava as convenções sociais como forma de fazer frente à esfera de julgamentos que rodeava sua vida e obra.

Além disso, ou por causa disso, Florbela não fez parte ativa do universo intelectual de seu tempo, inclusive do movimento modernista que começava a florescer. Acrescido ao que foi dito, havia o fato de viver afastada dos grandes centros, Lisboa especificamente, a precariedade de sua saúde e as dificuldades encontradas pelo simples fato de ser mulher (BENTO, 2008).

Entretanto, Florbela não deixou de se inscrever enquanto personalidade que abrilhanta, atualmente, o rol de intelectuais da literatura portuguesa para o cenário nacional e internacional. Situação que só começou a acontecer depois de seu suicídio, quando ganhou notoriedade com o livro Charneca em Flor, com a publicação de outros poemas e a exposição de suas cartas e diário, realizados por Battelli (DAL FARRA, 2002). 


\section{A Escrita Florbeliana: Uma Tentativa de Representação da Dor de Existir?}

Em certos poemas Florbela exprime a tristeza que traz consigo. Suas linhas ficcionais parecem encarnar os afetos: amor, medo, angústia e dor que seu Eu experimenta. Parte-se do pressuposto, portanto, que nas suas linhas ficcionais está presente "[...] Sua Majestade o [...] [Eu], o herói de todo devaneio e de todas as histórias" (FREUD, 2006 [1908], p. 140). Eu este que tentaria através da escrita, pelo artifício da linguagem, unir as pulsões em conflito através da atividade sublimatória e bloquear a energia agressiva a ele dirigida pelo Supereu.

No que se refere à expressão da melancolia na poesia florbeliana, muitos de seus poemas poderiam ser citados, mas para efeito de concisão destacaremos apenas dois poemas: "Mendiga", do Livro Charneca em Flor (1931), e "Deixai entrar a morte" da obra Reliquiae (1934). Acredita-se que estes versos refletem o estilo: forma e conteúdo a que Florbela representou a melancolia em sua escrita literária.

\section{MENDIGA}

Na vida nada tenho e nada sou; Eu ando a mendigar pelas estradas... No silêncio das noites estreladas Caminho, sem saber para onde vou!

Tinha o manto do sol... quem mo roubou?! Quem pisou minhas rosas desfolhadas?! Quem foi que sobre as ondas revoltadas A minha taça de oiro espedaçou?!

Agora vou andando e mendigando, Sem que um olhar dos mundos infinitos Veja passar o verme, rastejando...

Ah, quem me dera ser como os chacais Uivando os brados, rouquejando os gritos Na solidão dos ermos matagais!...

\section{DEIXAI ENTRAR A MORTE}

Deixai entrar a Morte, a Iluminada A que vem para mim, pra me levar. Abri todas as portas par em par Com asas a bater em revoada.

Que sou eu neste mundo? A deserdada A que prendeu nas mãos todo o luar, A vida inteira, o sonho, a terra, o mar E que, ao abri-las, não encontrou nada!

Ó Mãe! Ó minha Mãe, pra que nasceste? Entre agonias e em dores tamanhas Pra que foi, dize lá, que me trouxeste

Dentro de ti? Pra que eu tivesse sido Somente o fruto amargo das entranhas Dum lírio que em má hora foi nascido!...

Os versos apresentados exprimem as faces da melancolia encontradas a partir dos estudos dos teóricos da psicanálise: depreciação do sentimento de si advindo da energia da pulsão de morte sob os imperativos do Supereu que toma o Eu como objeto de gozo. Eu este que, não possuindo um significante que barre o gozo ou um objeto que favoreça a elaboração do luto, estando, ainda, identificado ao nada, acaba por assumir um masoquismo moral e um desejo inconsciente de punição e autodestruição pelo fato do sujeito ceder de seu desejo. 
Em Florbela a expressão da melancolia através da escrita ficcional e confessional parece ter sido empregada como tentativa de conter um excesso de gozo de um Supereu tirânico frente a um Eu submisso. Tentativa frustrada à medida que subjacente ao processo melancólico encontrar-se-ia um real que não pode ou não quer ser simbolizado. Uma impossibilidade de encontro com o significante binário na medida em que o significante unário está ausente. Impossibilidade de um encontro segundo na medida em que se baseia no encontro primeiro onde o olhar do bebê deparou com a ausência do olhar da mãe. A escrita, assim, fracassa em proporcionar alívio, e, ao contrário, torna-se testemunha de um enigma envolvendo disjunção pulsional e culpa.

Nesse sentido, Carvalho (2001) diz sobre a escrita que, ela pode fazer papel tanto de contenção quanto de excesso. Contenção das angústias e de um real que necessita ser elaborado, simbolizado, sublimado. Excesso de dor, de repetição e de mobilização das pulsões destrutivas. Portanto, a expensas de ser uma atividade sublimatória, "A escrita nem sempre é remédio, pois não barra integralmente as pulsões destrutivas, [...] pode se fazer poesia até a morte, pulsando a força da letra. A escrita ordena o pensamento, barra o gozo, mas não cura [...]” (BARROS, 2010, p. 126).

Assim, a repetição do mesmo e o tédio de viver, expresso na ficção, é posto em xeque na confissão que Florbela revela na sua correspondência e finalizada no real, no ato de autodestruir-se. Suicídio que para a poetisa, anos antes do ato fatal, já era considerado como possibilidade, refúgio da dor e demonstração de coragem ante os apelos da vida (DAL FARRA, 2002).

\section{Resultados e Discussão}

Com a pesquisa pôde-se compreender as nuances envolvendo a problemática da melancolia em Florbela Espanca. Onde se vê sobressair uma tendência ao desprezo e desdém para consigo mesma. Tendência esta que termina por gerar sentimento de incompatibilidade diante da vida.

Conquanto, vê-se desenhar na vida de Florbela algumas tentativas de saída da dor melancólica: refúgio na intelectualidade, desdém pelos investimentos no mundo externo, com renúncia aos passatempos e convenções sociais que isto implica, e apaixonamento. Tentativas que não lograram êxito. Quiçá pelo fato de haver uma ausência do significante mestre a barrar uma hemorragia libidinal causada pelo gozo mortífero do Supereu. Quiçá pelas tentativas de 
produzir um objeto, encarnado em verso e prosa, que a permitisse elaborar a dor, vivenciar o luto do objeto que não se perdeu posto estar ausente desde o início.

A escrita, neste sentido, poderia representar uma maneira de sublimar, conciliar ou unir as pulsões de vida e a pulsão de morte. Entretanto, a escrita literária e confessional em Florbela parece refletir a tristeza e a dor profunda que sentia. Atividade que poderia ser interpretada enquanto modo de conter um real dilacerante, como exemplo: a insólita situação de seu nascimento, os dois abortos sofridos, os problemas orgânicos decorrentes, a morte de seu irmão, as desilusões afetivas que a fizeram casar três vezes e ainda assim sentir-se sozinha.

Além disso, sua escrita parece servir para dar ordem a um excesso de conflito entre Supereu e Eu. Onde em momentos vê-se triunfar o Eu de sua condição submissa e noutros vêse cair, culpado de um crime que não sabe situar a origem, frente às acusações e ditames do Supereu.

No que se refere à investigação da posição subjetiva de Florbela pertencer à neurose atual, narcísica ou à psicose, não se pôde compreender ao certo por um motivo em particular: o estudo realizado sobre sua história de vida baseou-se apenas em suas cartas e poemas; ou seja, em seus ditos e não em seu dizer.

Não obstante, acredita-se que a melancolia padecida por Florbela Espanca desde tenra idade foi alimentada pelo fato de buscar na arte, especificamente na literatura, dar sentido ao caos que considerava a própria vida. Talvez porque percebesse na porta da arte uma possibilidade de conciliar pulsões de vida e de morte em conflito, além de entrar nos laços sociais através do reconhecimento de sua qualidade literária pelos críticos e público da época. Possibilidade esta que não ocorreu durante sua vida, onde, isto sim, era perseguida e maltratada por expressar na escrita o que havia em seu íntimo. Sendo considerada, para muitos de sua época, um péssimo modelo do feminino.

É assim que o ato suicida da escritora, pensado aqui enquanto possibilidade de dizer no real o que a linguagem, manifestação do simbólico, não conseguiu, parece ter servido para atrair seus contemporâneos aos efeitos técnicos de sua poética e valorização de sua escrita para a posteridade à revelia de seus detratores. Ademais, mesmo à custa da própria vida o conflito entre Eu e Supereu acabou por ser reduzido a zero. 


\section{Considerações finais}

O presente artigo não pretendeu esgotar os estudos realizados sobre a melancolia tampouco sobre a vida e a obra de Florbela Espanca; porém, fomentar a discussão na academia ante uma problemática de difícil manejo clínico tanto pelo fato de estar associada a outras patologias como anorexia, hipocondria, abulia e distúrbios do sono quanto pelo fato de o melancólico procurar mascarar seu padecimento e seus planos de suicídio.

Foi trabalhada a temática da melancolia em Florbela que padeceu desse mal: mal de amor, fardo de viver.

Florbela Espanca sofreu de uma profunda tristeza. Que aparentemente perpassou a atividade dos artistas de fim de século que não podendo dar livre curso a seus anseios acabavam por recorrer à arte na tentativa de ver, pela via da fantasia, seus desejos alcançados.

No caso da poetisa, sua tendência artística não parece ter contribuído para abrandar seus padecimentos, até em virtude das questões envolvendo a situação da mulher portuguesa no final do século XIX e início do século XX, onde era proibido à mesma manifestar ostensivamente seus sentimentos e pensamentos. Especialmente da forma que Florbela representou com toques de erotismo, de egotismo, de destrutividade e de morte.

Sua escrita literária e confessional, especificamente seus versos e cartas: que foram objeto de análise neste trabalho, encarnavam as faces que ela interpretava em seu cotidiano e a real fisionomia de seu estado de humor. As faces foram desaparecendo em suas relações sociais na medida em que seu processo melancólico a arrastava do convívio com os seres humanos e a empurrava para uma atividade intelectual que não lhe rendia fruto algum, e para o culto à morte enquanto possibilidade de libertação. Assim é que alguns de seus poemas terminavam por retratar uma angústia sempre crescente e a necessidade de por termo à vida e mergulhar no sono profundo e eterno da morte.

Enfim, a melancolia que conduziu Florbela à morte é a mesma melancolia, hoje também associada à depressão, que ceifa a vida de muitas pessoas, direta ou indiretamente, pela perda do sentido da vida, da vontade de viver e de se responsabilizar pelos próprios desejos. Se é uma neurose atual, narcísica ou uma psicose, não se chegou a uma resposta única. O fato é que sempre existiu e, enquanto em algumas pessoas pode retroceder espontaneamente, pela via da arte, pelo tratamento analítico e/ou medicamentoso, em outras, a exemplo de Florbela, pode levar, malgrado os esforços por parte do sujeito, ao suicídio. 


\section{Referências}

BARROS, E. L. S. Os enigmas do dizer poético de Florbela Espanca. In. Psicanálise \& Barroco em revista, v.8, n.1, 2010. Disponível em: $<$ http://www.psicanaliseebarroco.pro.br/revista/revistas/15/P\&Brev15Barros.pdf.> Acesso em: 01 set. $2011,17: 20$.

BRASIL, M. A. Fora de si, Fora do mundo. In. Os nomes da tristeza. Revista da associação psicanalítica de Porto Alegre, Ano IX, n. 21. Porto Alegre: APPOA, 2001. Disponível em: <http://www.appoa.com.br/download/revista21.pdf>. Acesso em: 14 set. 2011, 18:30.

BENTO, E. R. Melancolia e poesia tecidas em flor e anjos: diálogo melancólico entre as poéticas de Augusto dos Anjos e Florbela Espanca. Campina Grande: UEPB, 2008. Dissertação (mestrado). Disponível em: 〈httpll:www.ppgli.uepb.edu.br.pdf>. Acesso em: 25 jul. 2011, 18:00.

CARVAlHO, A. C. Pulsão e simbolização: limites da escrita. In. BARTUCCI, G. (Org.). Psicanálise, literatura e estéticas de subjetivação. Rio de Janeiro: Imago, 2001.

CARNEIRO, H. F., et al. Melancolia, ressentimento e laço social: repercussões na clínica psicanalítica. In. Revista mal-estar e subjetividade. Fortaleza, v. VI, n. 2, 2006.

COSTA, T. A contribuição de Jacques Lacan. In. Psicanálise com Crianças. 3 ed. Rio de Janeiro: Zahar, 2010 (Coleção passo-a-passo).

DAL FARRA, M. L. (Org.). Afinado desconcerto (contos, cartas, diário). Florbela Espanca. São Paulo: editora iluminuras ltda, 2002 (coleção vera cruz).

ESPANCA, F. Livro de mágoas (1913). Sonetos. Amadora, Portugal: Bertrand, 1978. Disponível em: <http://www.dominiopublico.gov.br>. Acesso em: 01 set. 2011, 19:00.

_. Livro de Sóror Saudade (1923). Disponível em: < http://www.dominiopublico.gov.br >. Acesso em: 02 set. 2011, 10:00. 
Charneca em flor Disponível em: < http://www.dominiopublico.gov.br >. Acesso em: 01 set. 2011, 20:30. 1931.

Reliquiae. Publicado como apêndice nas $2^{\mathrm{a}}$ e $3^{\mathrm{a}}$ edições de Charneca em flor. Disponível em: <http://www.dominiopublico.gov.br>. Acesso em: 01 set. 2011, 21:00. 1934.

FARIA FILHO, C. A. Florbela Espanca: mundo e forma. Faculdade de Letras da Universidade Federal de Goiás. Goiânia, 2006. Dissertação (mestrado). Disponível em: <http l::www.letras.ufg.br.pdf>. Acesso em: 25 jul. 2011, 15:00.

FREUD, S. Extratos dos documentos dirigidos a Fliess (1950[1892-1899]). In. Publicações pré-psicanalíticas e esboços inéditos (1886-1899). Edição standard brasileira das obras psicológicas completas de Sigmund Freud. Rio de Janeiro: Imago, 2006.

Escritores criativos e devaneios (1908). In. "Gradiva" de Jensen e outros trabalhos (1906-1908). Edição standard brasileira das obras psicológicas completas de Sigmund Freud. Rio de Janeiro: Imago, 2006.

Luto e melancolia (1917). In. Escritos sobre a psicologia do inconsciente. Volume II (1915-1920). Rio de Janeiro: Imago, 2006.

- Além do princípio de prazer (1920). In. Escritos sobre a psicologia do inconsciente. Volume II (1915-1920). Rio de Janeiro: Imago, 2006.

O ego e o id (1923). In. O ego e o Id e outros trabalhos (1923-1925). Edição standard brasileira das obras psicológicas completas de Sigmund Freud. Rio de Janeiro: Imago, 2006.

O problema econômico do masoquismo (1924). In. Escritos sobre a psicologia do inconsciente. Volume III (1923-1938). Rio de Janeiro: Imago, 2007.

O mal-estar na civilização (1930). In. O futuro de uma ilusão, o mal-estar na civilização e outros trabalhos (1927-1931). Edição standard brasileira das obras psicológicas completas de Sigmund Freud. Rio de Janeiro: Imago, 2006. 
A dissecção da personalidade psíquica (1933). In. Novas conferências introdutórias sobre psicanálise e outros trabalhos (1932-1936). Edição standard brasileira das obras psicológicas completas de Sigmund Freud. Rio de Janeiro: Imago, 2006.

FINK, B. O sujeito lacaniano: entre a linguagem e o gozo. Rio de janeiro: Jorge Zahar Ed., 1998.

GARCIA-ROZA, L. A. O mal radical em Freud. $5^{\text {a }}$ edição. Rio de janeiro: Jorge Zahar Ed., 2004.

GARMES, H., e SIQUEIRA, J. C. Saudade e saudosismo na Literatura Portuguesa. In. Cultura e memória na literatura portuguesa. Curitiba: IEDES Brasil S. A., 2009. Disponível em: <http://www2.videolivraria.com.br/pdfs/24005.pdf> Acesso em: 24 out. 2011, 14:00.

GIL, A. C. Métodos e técnicas de pesquisa social. São Paulo: Atlas, 1999.

HASSOUN, J. A crueldade melancólica. Rio de Janeiro: Civilização brasileira, 2002.

LACAN, J. Escritos. Rio de Janeiro: Jorge Zahar Ed., 1998.

MORENO, E. B. A loucura e o feminino na obra de Florbela Espanca. Universidade do Estado do Rio de Janeiro. Instituto de letras, 2007. Dissertação (mestrado). Disponível em: <http \:www.bdtd.uerj.br.pdf>. Acesso em: 25 jul. 2011, 16:30.

MANNONI, O. O mistério da culpa. In. Freud: uma biografia ilustrada. Rio de Janeiro: Jorge Zahar Ed., 1994.

OLIVEIRA, M. M. Como fazer pesquisa qualitativa. $2^{\text {a }}$ ed. Petrópolis, Rio de Janeiro: Vozes, 2008.

QUINET, A. Psicose e laço social: esquizofrenia, paranóia e melancolia. $2^{\mathrm{a}}$ ed. Rio de Janeiro: Jorge Zahar Ed., 2009. 
RAMALHO, R. M. A vida por um fio. In. Os nomes da tristeza. Revista da associação psicanalítica de Porto Alegre, Ano IX, n. 21. Porto Alegre: APPOA, 2001. Disponível em: <http://www.appoa.com.br/download/revista21.pdf>. Acesso em: 14 set. 2011, 19:00.

ROUDINESCO, E., e PLON, M. Dicionário de Psicanálise. Rio de Janeiro: Zahar, 1998. Valas, P. As dimensões do gozo. Rio de Janeiro: Jorge Zahar Ed., 2001.

\section{NOTAS}

${ }^{1}$ Às duas horas, mesma hora em que veio ao mundo, Florbela, com trinta e seis anos completos, dá fim à vida através da overdose de Veronal. Barbitúrico recomendado por seu marido (Mário Pereira Lage, que era médico) desde 1927, para abrandar os sintomas de tristeza apresentados por ela quando da morte do irmão.

${ }^{2}$ Poeta português.

${ }^{3}$ Os autores citam ainda Francisco Manoel de Melo (1608-1666), um dos expoentes do barroco português, a fim de explicar a causa do sentimento de saudade aparentemente presente no povo de Portugal, causa que traria consigo uma mistura de prazer e dor. Nesse sentido, a saudade surgiria devido ao amor e à ausência. Amor, posto que os portugueses amassem com maior intensidade. Ausência, devido às viagens marítimas que isolavam e distanciavam os homens de sua terra por grandes intervalos de tempo (Garmes, \& Siqueira, 2009).

\section{Sobre os Autores:}

(1) Débora dos Santos Silva é Psicóloga da Secretaria de Assistência Social do Município de Iguatu - CE. E-mail: djuziro@hotmail.com;

(2) Raul Max Lucas da Costa é Docente do Curso de Psicologia da Faculdade Leão Sampaio, Juazeiro do Norte, Ceará. Psicólogo da Secretaria de Saúde do Município de Juazeiro do Norte - CE.

E-mail: raulmaxpsi@yahoo.com.br.

\section{Como citar este artigo (Formato ISO):}

SILVA, D.S. e COSTA, R.M.L. As Faces Da Melancolia: Pulsão De Morte, Supereu e Ato em Florbela Espanca. Id on Line Revista de Psicologia, Julho de 2012, vol.1, n.17, p. 05-24. ISSN 1981-1189. 